\title{
Effect of Cold Working on Creep Rupture Strength of Alloy 617
}

\author{
Yoshiki Shioda $^{1}$, Kyohei Nomura ${ }^{1}$, Keiji Kubushiro ${ }^{1}$, Yoshinori Murata ${ }^{2}$ \\ ${ }^{1}$ Research Laboratory, Materials Department, IHI Corporation, Yokohama, Japan \\ ${ }^{2}$ Department of Materials, Physics and Energy Engineering, Nagoya University, Nagoya, Japan
}

Email address:

yoshiki_shioda@ihi.co.jp (Y. Shioda)

\section{To cite this article:}

Yoshiki Shioda, Kyohei Nomura, Keiji Kubushiro, Yoshinori Murata. Effect of Cold Working on Creep Rupture Strength of Alloy617. International Journal of Materials Science and Applications. Vol. 6, No. 4, 2017, pp. 178-189. doi: 10.11648/j.ijmsa.20170604.13

Received: May 26, 2017; Accepted: June 8, 2017; Published: June 29, 2017

\begin{abstract}
The effect of cold working on the creep rupture strength of Alloy617 was investigated. The creep rupture tests were conducted at temperatures of 700 to $800^{\circ} \mathrm{C}$, under stresses from 100 to $350 \mathrm{MPa}$. At high stress conditions, the creep rupture time of the non-pre-strained samples are similar to those of the pre-strained samples. On the other hand, at low stress conditions, the creep rupture time of the pre-strained samples are longer than those of the non-pre-strained samples. The amount of precipitates near the grain boundaries in the pre-strained sample is higher than that in the non-pre-strained sample. Weak regions such as PFZ and recrystallization grains in the non-pre-strained sample are formed in the early stage of creep compared to the pre-strained sample. At low stress conditions, the precipitates near the grain boundaries in the pre-strained sample play an effective role to pin the grain boundaries and they delay the formation of the weak regions resulting in extension to the creep rupture time.
\end{abstract}

Keywords: A-USC, Alloy617, Pre-strain, Cold Working, Creep Strength, Microstructure

\section{Introduction}

Recently, for coal-fired power plants, the high temperature steam conditions are required for the reduction of $\mathrm{CO}_{2}$ emissions and high efficiency of the plants. As a step up from the current $600^{\circ} \mathrm{C}$ class Ultra Super Critical (USC) boilers [1], technology to Advanced-Ultra Super Critical (A-USC) boilers are being developed [2-8]. In A-USC boilers, $700^{\circ} \mathrm{C}$ steam which is $100^{\circ} \mathrm{C}$ higher than the steam used in USC boilers, is used. Both the ferritic heat-resistant steels and austenitic heat-resistant steels are not suitable for this steam temperature of A-USC boilers. Therefore, Ni based alloys which have high strength and corrosion resistance are planned to use in A-USC boilers. As the $\mathrm{Ni}$ based alloy, currently, Alloy617 (Ni-22Cr-12.5Co-9Mo alloy) is receiving attention as a candidate material for A-USC boilers. Precipitates in Alloy 617 are mainly $\gamma^{\prime}$ phase $\left(\mathrm{Ni}_{3}(\mathrm{Al}, \mathrm{Ti})\right), \mathrm{M}_{23} \mathrm{C}_{6}$ carbide, $\mathrm{M}_{6} \mathrm{C}$ carbide and $\mathrm{Ti}(\mathrm{C}, \mathrm{N})$ carbonitride. It is reported that the creep strength is affected considerably by the precipitation of $\gamma$, phase at temperatures below approximately $800^{\circ} \mathrm{C}$ [9-12]. This alloy has high creep-rupture strength for up to 100,000 hours at $700^{\circ} \mathrm{C}$ and the strength is approximately $100 \mathrm{MPa}$.
However, Ni based alloys have not been used in boilers thus far. In addition, boiler tubes are cold-worked during fabrication. Therefore, it is necessary to clarify the effect of cold working on long-time creep-rupture strength of $\mathrm{Ni}$ based alloys, because this effect varies significantly depending from alloy to alloy $[13,14]$. Furthermore, there are some reports about the effect of cold working on creep rupture strength of ferritic heat-resistant steels and austenitic heat-resistant steels [15-17], but very few reports exist about that of Alloy617. In addition, most of creep tests in the previous papers were conducted at temperatures of 850 to $1000^{\circ} \mathrm{C}$, which is much higher than the temperature conditions of A-USC. [18, 19].

The purposes of this paper are to clarify the effect of cold working on the creep rupture strength, the creep deformation behavior and the change in microstructure of pre-strained Alloy617. For those purposes, the pre-strained Alloy617 was prepared via interrupted tensile test and was used for the creep rupture and interruption tests.

\section{Experimental Procedures}

In this study, Alloy617 tube material with an outer diameter of $38 \mathrm{~mm}$ and a wall thickness of $11 \mathrm{~mm}$ was used 
as a test material. The tube was subjected to solution heat treatment at $1200^{\circ} \mathrm{C}$ for $22 \mathrm{~min}$. The chemical composition of
Alloy617 is shown in Table 1.

Table 1. The Chemical composition of Alloy617.

$(w t, \%)$

\begin{tabular}{|c|c|c|c|c|c|c|c|c|c|c|c|}
\hline Alloy & $\mathrm{C}$ & $\mathrm{Ni}$ & $\mathrm{Cr}$ & Mo & Co & Al & $\mathbf{T i}$ & $\mathbf{S i}$ & $\mathbf{F e}$ & Mn & B \\
\hline Alloy617 & 0.059 & Bal. & 21.90 & 8.66 & 11.70 & 0.97 & 0.42 & 0.07 & 0.94 & 0.04 & 0.003 \\
\hline
\end{tabular}

Alloy617 has equiaxial grains of approximately $100 \mu \mathrm{m}$ and there are no precipitates in the grains. Few undissolved carbides are only observed.

For simulating the cold work, the tube was processed into arc-shaped tensile test specimens. The arc-shaped specimens were parallel portion with a width $15 \mathrm{~mm}$, a thickness $11 \mathrm{~mm}$, and a gauge distance $80 \mathrm{~mm}$. Tensile interrupted tests were carried out on them. The specimens were subjected to pre-strain of $30 \%$. The strain rate is $1.67 \times 10^{-3} \mathrm{~s}^{-1}$. Figure 1 shows a representative result showing the relationship between stress and interrupted tensile strain.

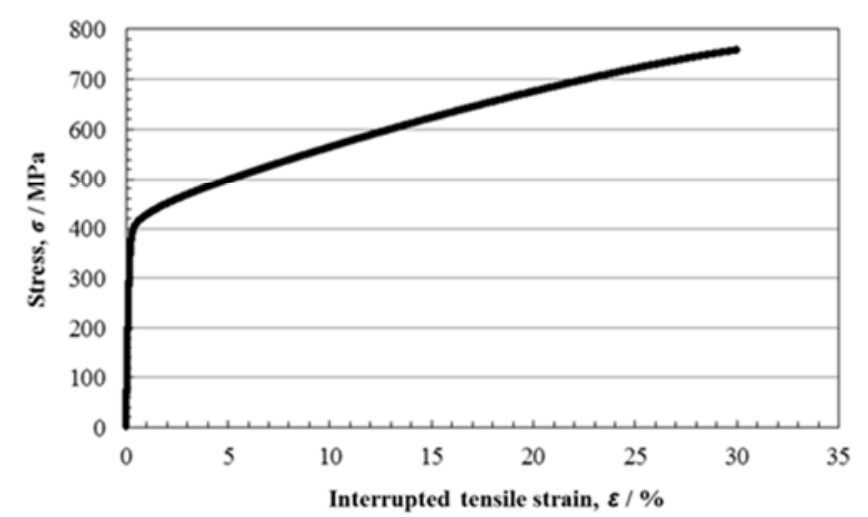

Figure 1. Relationship between stress and interrupted tensile strain.

Non-uniform deformation was not observed in the interrupted specimens. The specimens subjected to pre-strain of $30 \%$ in a tensile test at room-temperature are referred to as the pre-strained specimens, while the specimens that are not subjected to the pre-strain are referred to as the non-pre-strained specimens. The Vickers hardness of the non-pre-strained specimen and the pre-strained one are 205 and $332 \mathrm{HV}$, respectively. After the interrupted tensile test, the parallel portion of each test specimen was re-processed into a specimen with gauge length of $30 \mathrm{~mm}$ and a parallel portion of $6 \mathrm{~mm}$ for creep rupture tests. The creep rupture tests were conducted at temperatures of 700 to $800^{\circ} \mathrm{C}$, under stresses from 100 to $350 \mathrm{MPa}$. The samples were maintained for 2 hours at test temperature before the creep tests were started. The samples tested at $700^{\circ} \mathrm{C}$ under $350 \mathrm{MPa}$ were conducted until ruptured and the creep test at $750^{\circ} \mathrm{C}$ under 170 MPa was interrupted after 997 hours. Each creep test sample was cut such that the surface to be observed was parallel with the stress axis. Microstructure observation and electron back scatter diffraction (EBSD) measurement were used on the samples. Microstructures of the samples were observed with a scanning electron microscope (SEM) and a scanning transmission electron microscope (STEM). For the EBSD measurement, the pitch was $0.2 \mu \mathrm{m}$ and the measurement range was $200 \times 200 \mu \mathrm{m}$.

\section{Experimental Results and Discussion}

\subsection{Influence of Pre-strain on Creep Rupture Strength}

Figure 2 shows the effect of the pre-strain on the creep rupture strength. The vertical axis and the horizontal axis are the stress and creep rupture time, respectively.

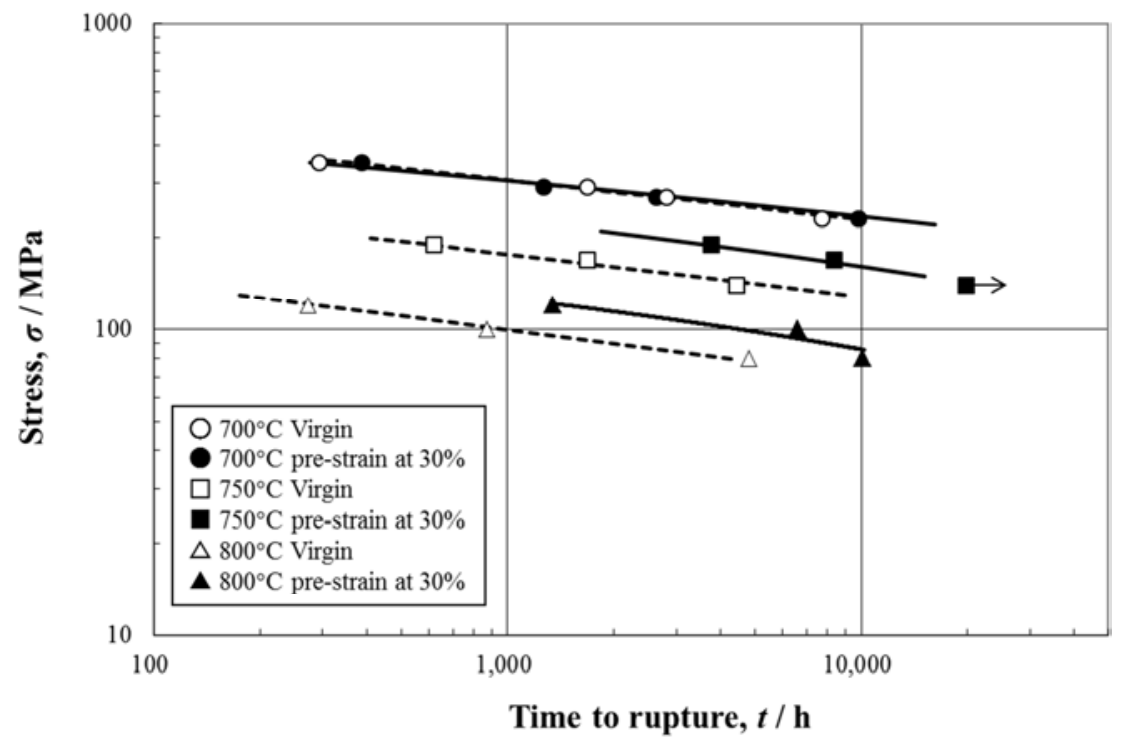

Figure 2. The effect of plastic strain on creep rupture strength in Alloy617. 
At high stress conditions, no significant difference was seen in the creep rupture strength between the pre-strained and non-pre-strained samples. Meanwhile, at low stress conditions, the pre-strained samples exhibited higher creep rupture strength compared to the non-pre-strained samples.
This figure shows that the effect of cold working on the creep rupture strength is different between high and low stress conditions. To clarify the causes, creep strain tests were conducted at $700^{\circ} \mathrm{C}$ under $350 \mathrm{MPa}$ and $750^{\circ} \mathrm{C}$ under 170 $\mathrm{MPa}$. Figure 3 shows the creep rate-time curves.

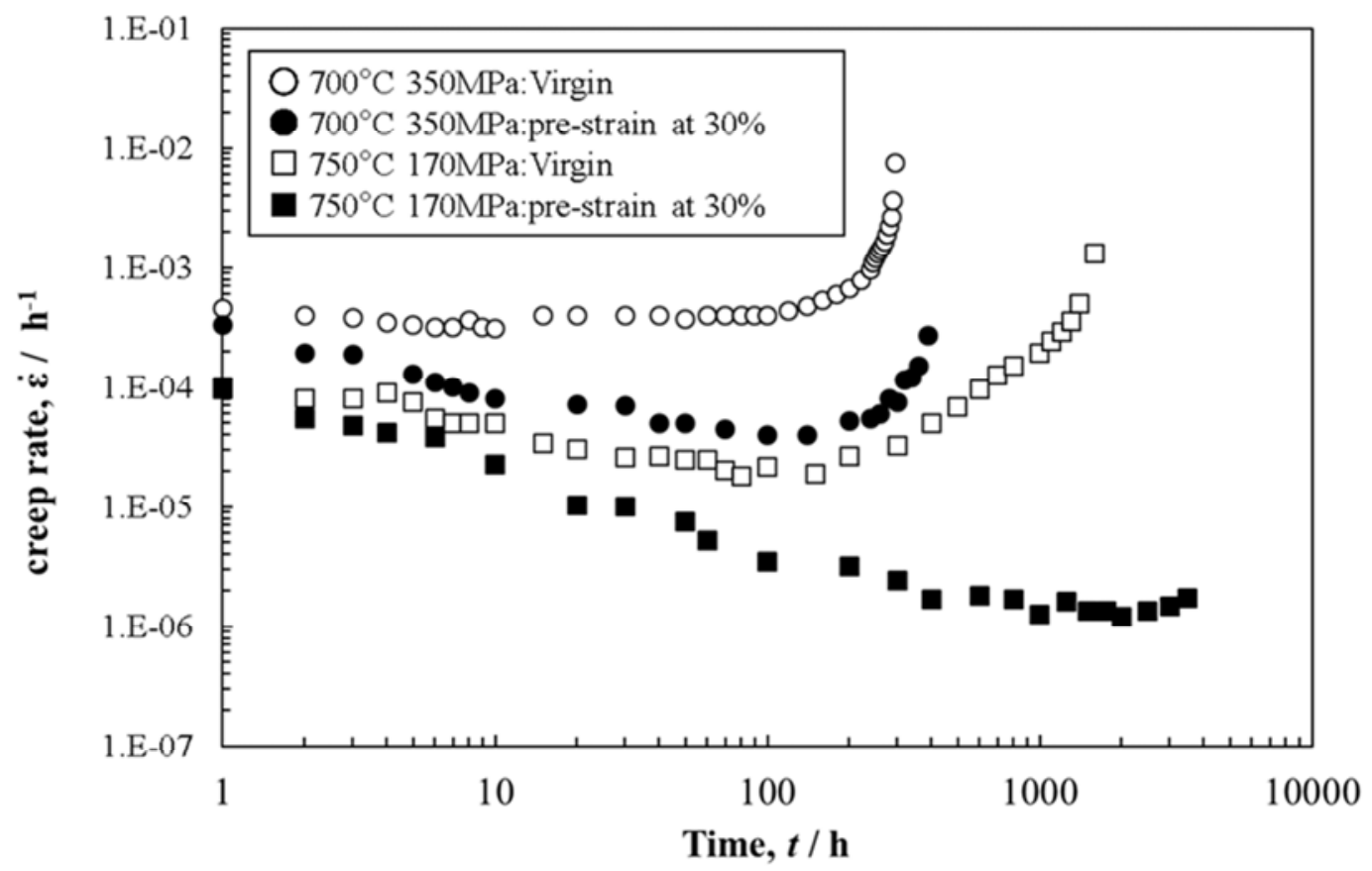

Figure 3. Creep rate - time curves of pre-strained alloys and virgin alloys at $700^{\circ} \mathrm{C}, 350 \mathrm{MPa}$ and $750^{\circ} \mathrm{C}, 170 \mathrm{MPa}$.

Under both creep conditions, the transient creep rate of the pre-strained samples is smaller than that of the non-pre-strained samples and the minimum creep rate is smaller by approximately one order of magnitude. The figure also shows that both the time to reach the minimum creep rate and the time at which accelerating creep begins, are delayed for the pre-strained samples. In addition, comparing the pre-strained samples to the non-pre-strained samples, the creep deformation behaviors after acceleration varied dependently on the stress. Specifically, at $750^{\circ} \mathrm{C}$ under 170 $\mathrm{MPa}$, the creep rate of the pre-strained sample did not rapidly increase after accelerating creep began, unlike the non-pre-strained sample. On the other hand, at $700^{\circ} \mathrm{C}$ under $350 \mathrm{MPa}$, the creep deformation behaviors after the accelerating creep of both samples were similar to each other. This shows the effect of pre-strain on creep rupture strength is different between the high stress condition and the low stress condition, because the creep deformation behavior of the pre-strained sample after the acceleration of creep rate at the high stress condition is not similar to that at the low stress condition.

To consider the reason why the creep rate of the pre-strained samples is smaller than that of the non-pre-strained samples, the instantaneous strain in creep tests were examined. Figure 4 shows the relationship between the instantaneous strain and the load stress when stress was applied.

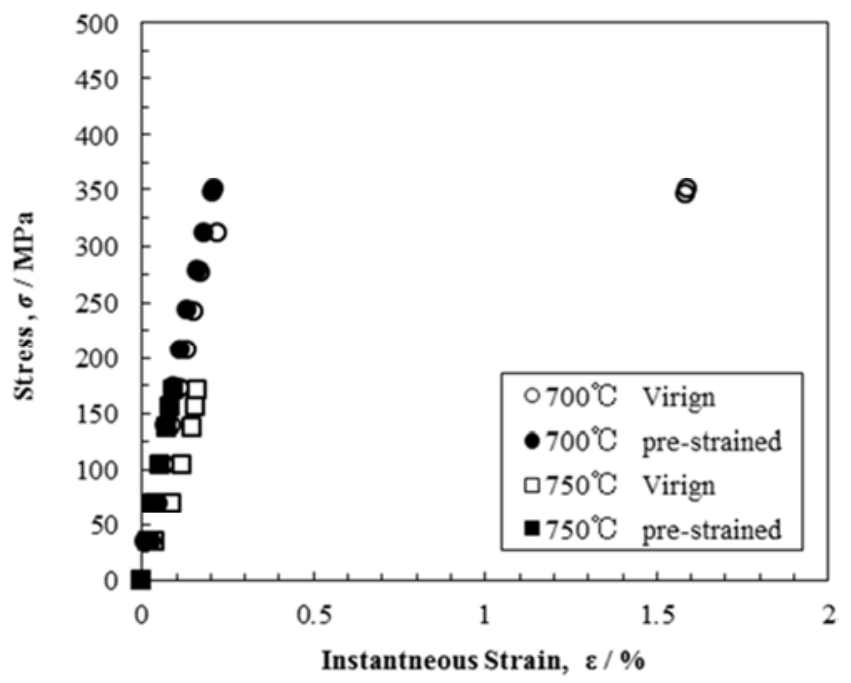

Figure 4. Comparison of instantaneous strains of pre-strained samples with virgin samples.

On the non-pre-strained sample remarked "Virgin" in the figure, an instantaneous plastic strain occurred at around a load stress of $300 \mathrm{MPa}$, but such strain did not occur on the pre-strained sample. This means that hardening occurs in the pre-strained samples due to dislocations introduced by cold working. In the next section, microstructures are observed to confirm whether the difference in fracture morphology and in microstructure between both samples exists or not. 


\subsection{Fracture Morphology and the Initiation Point of Fracture of the Ruptured Samples}

Figure 5 shows fracture morphology taken from (a) non-pre-strained sample, (b) pre-strained sample (test conditions: $700^{\circ} \mathrm{C}$, $350 \mathrm{MPa}$ ), (c) non-pre-strained sample and (d) pre-strained sample (test conditions: $750^{\circ} \mathrm{C}, 170 \mathrm{MPa}$ ).
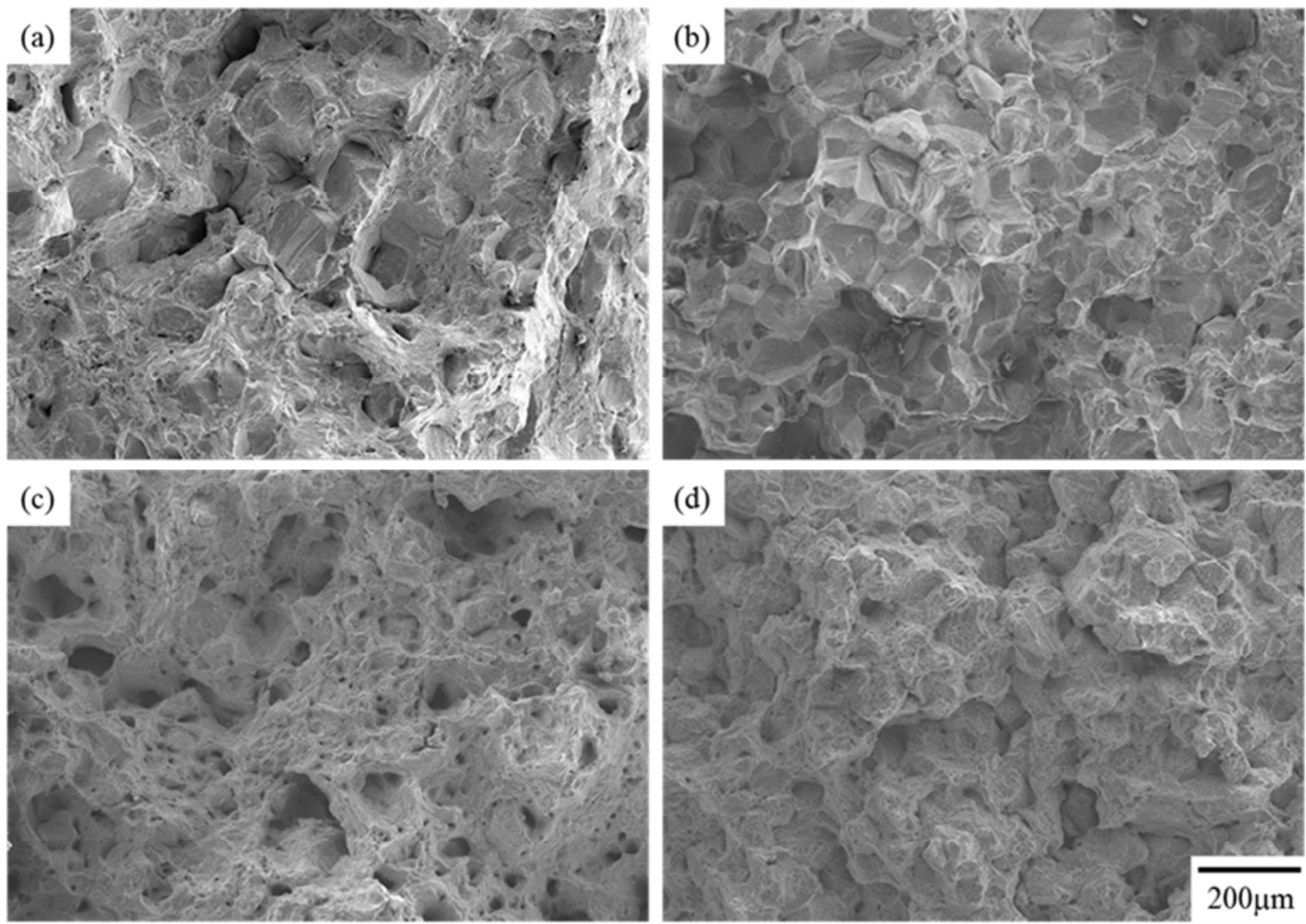

Figure 5. Secondary electron images of fracture surface in Alloy617 ruptured at $700^{\circ} \mathrm{C}, 350 \mathrm{MPa}\left((\right.$ a) virgin, (b) pre-strain at $30 \%)$ and $750^{\circ} \mathrm{C}, 170 \mathrm{MPa}((\mathrm{c})$ virgin, (d) pre-strain at 30\%).

Comparing (a) to (b), dimples and intergranular cracking are seen on the fracture surface of the non-pre-strained sample, whereas intergranular cracking are observed on that of the pre-strained sample. Comparing (c) to (d), the non-pre-strained sample shows dimples in the fracture surface, but the pre-strained sample shows dimples and intergranular cracking in the fracture surface. To clarify the

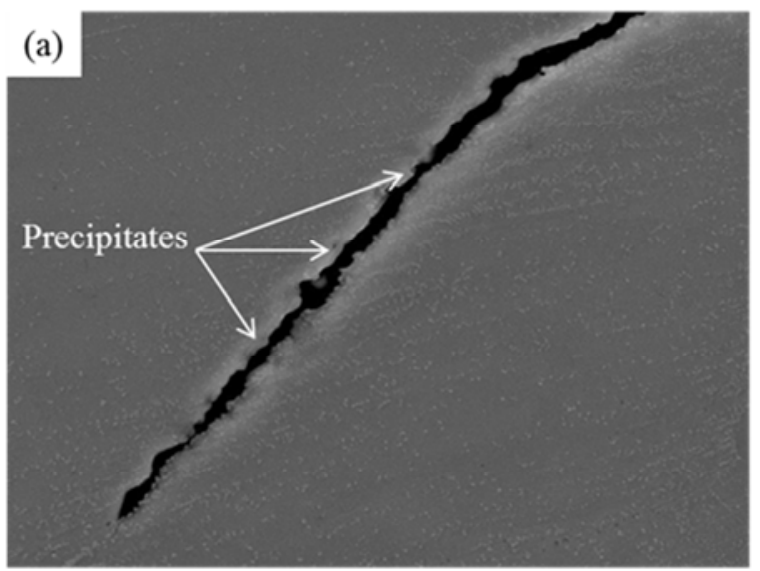

causes of this difference, each ruptured sample was observed using a SEM while attention was paid to the area where the crack had initiated.

Figure 6 shows SEM images of the samples ruptured at $700^{\circ} \mathrm{C}$ under $350 \mathrm{MPa}$. (a) is the non-pre-strained sample and (b) is the pre-strained sample.

\section{(b)}

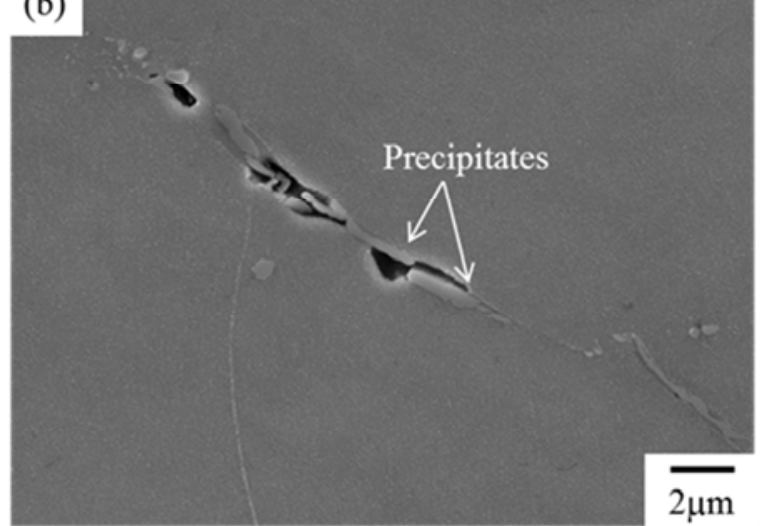

Figure 6. Secondary electron images of Alloy 617 ruptured at $700^{\circ} \mathrm{C}, 350 \mathrm{MPa}$ (a) virgin, (b) pre-strain at $30 \%$. 
For both samples, cracks initiated at the interface between the matrix and the grain boundaries or at the grain boundary without precipitates.

Figure 7 shows SEM images of intragranular grain for the samples ruptured at $700{ }^{\circ} \mathrm{C}$ under a stress of $350 \mathrm{MPa}$. (a) is the non-pre-strained sample and (b) is the pre-strained sample.
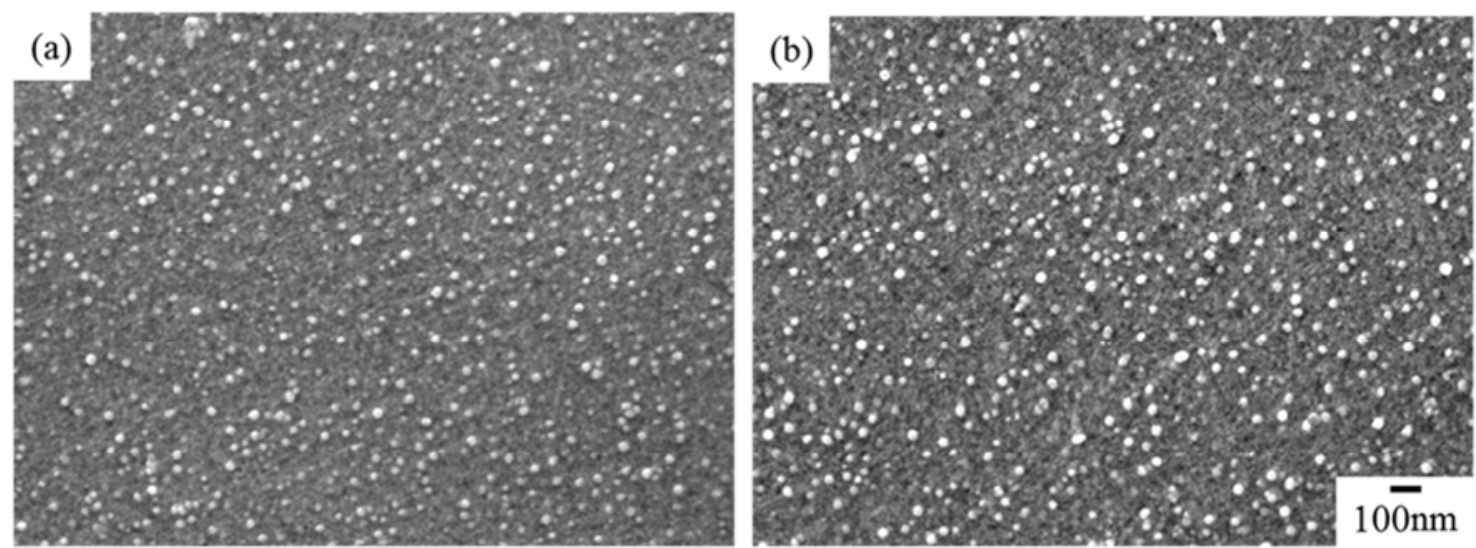

Figure 7. Secondary electron images of intragranular grain for Alloy 617 ruptured at $700^{\circ} \mathrm{C}, 350 \mathrm{MPa}$ (a) virgin, (b) pre-strain at $30 \%$.

For both samples, fine $\gamma^{\prime}$ phase was precipitated in the grains, and no significant difference was observed in the microstructure.

Figure 8 shows SEM images of the samples ruptured at $750{ }^{\circ} \mathrm{C}$ under $170 \mathrm{MPa}$. (a) and (b) show the initial crack location on the non-pre-strained sample and the pre-strained sample, respectively. (c) and (d) show the grain boundaries in the non-pre-strained sample and in the pre-strained sample, respectively.

(a)

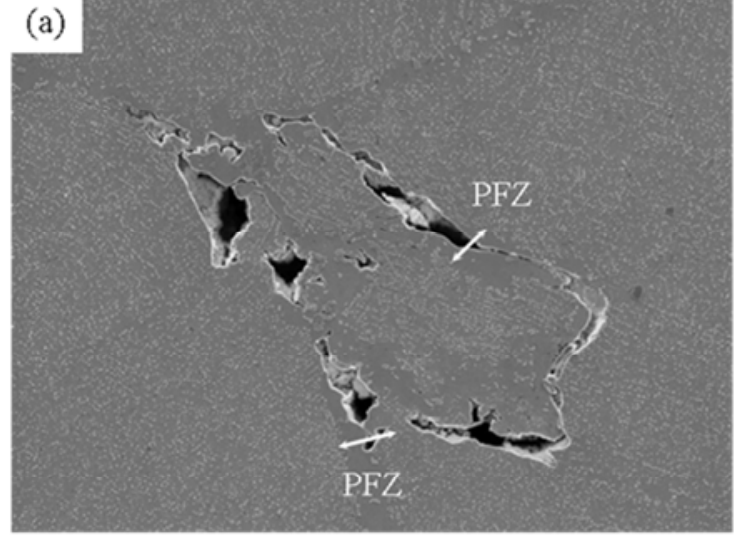

(c)

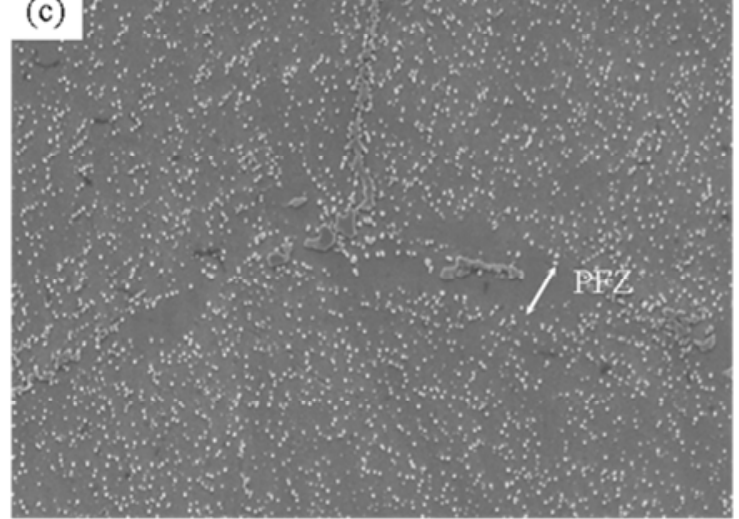

(b)

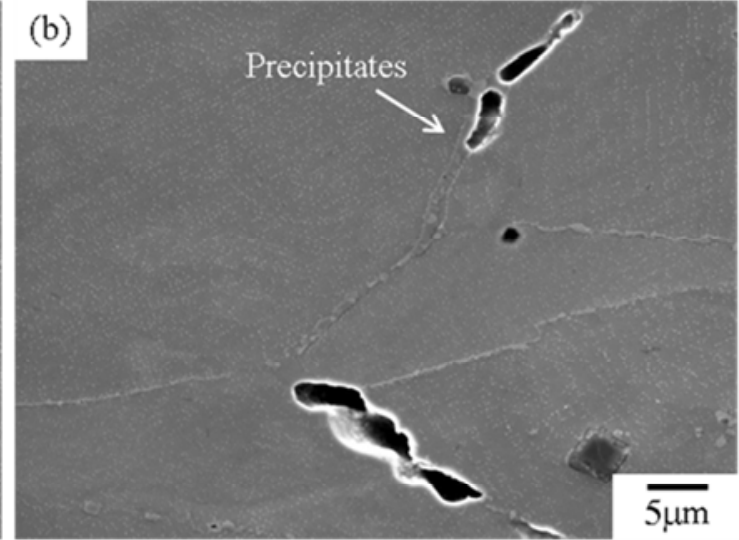

(d)

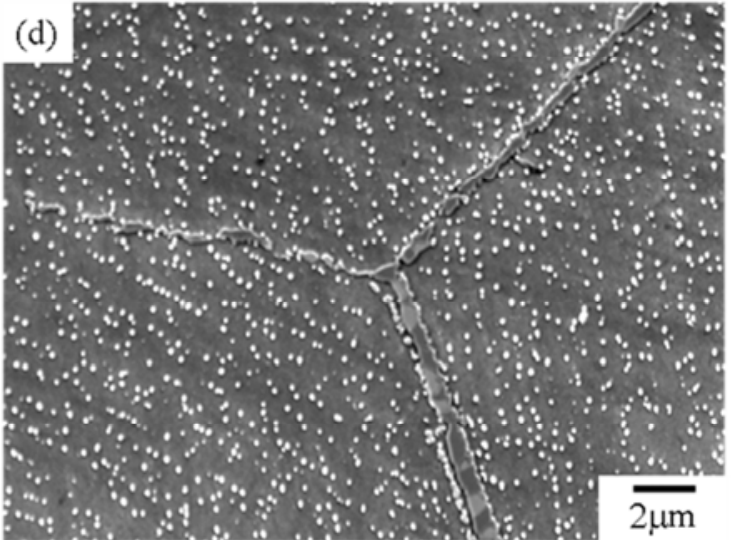

Figure 8. Secondary electron images of crack initiation position ((a) virgin, (b) pre-strain at 30\%) and grain boundaries ((c) virgin, (d) pre-strain at 30\%) for Alloy617 ruptured at $750^{\circ} \mathrm{C}, 170 \mathrm{MPa}$.

It is found again that the cracks initiated along precipitation free zones (PFZ) in the non-pre-strained sample. On the other hand, cracks initiated at the interfaces between matrix and the grain boundaries or at the grain boundary without precipitates 
in the pre-strained sample. It is also found that the amount of precipitates at the grain boundaries in the non-pre-strained sample is observed to be smaller than that in the pre-strained sample. However, the rupture time of the sample in Figure 8(c) is different from that in Figure 8(d), and hence the detailed microstructures were compared using test samples for which

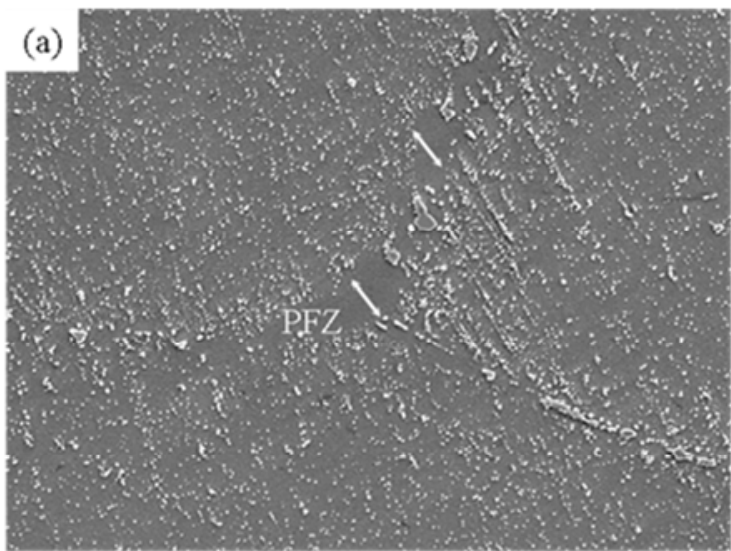

the creep test was interrupted after the same time.

\subsection{Microstructures of the Interrupted Samples}

Figure 9 shows SEM images of the interrupted samples (test conditions: $750^{\circ} \mathrm{C}, 170 \mathrm{MPa}$, interrupted after 997 hours).

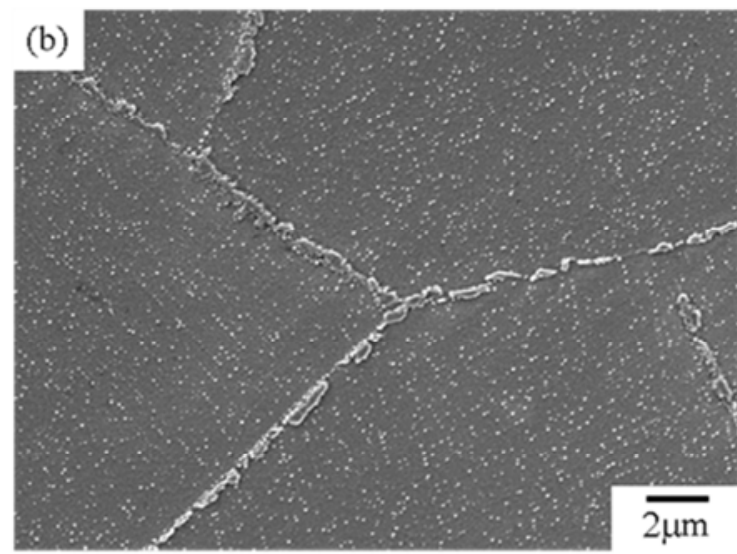

Figure 9. Secondary electron images of Alloy 617 interrupted at $750^{\circ} \mathrm{C}, 170 \mathrm{MPa}(t=997 \mathrm{~h}$, (a) virgin, (b) pre-strain at $30 \%)$.

Figure 9(a) shows PFZ near the grain boundaries in the non-pre-strained sample, as is the case with the ruptured sample shown in Figure 8. However, no PFZ is seen in the pre-strained sample as is seen in Figure 9(b). In addition, the amount of precipitates at the grain boundaries in the pre-strained sample is larger than that in the non-pre-strained sample. As shown above, despite the same creep time, the amount of precipitates near the grain boundaries varies by the
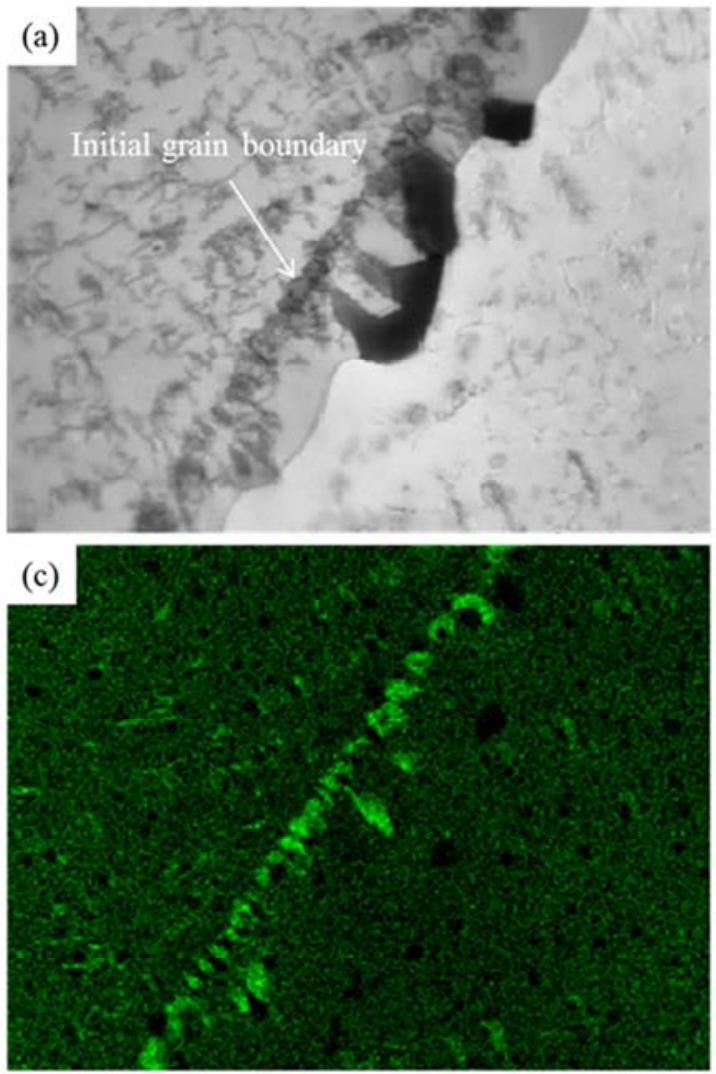

(d)
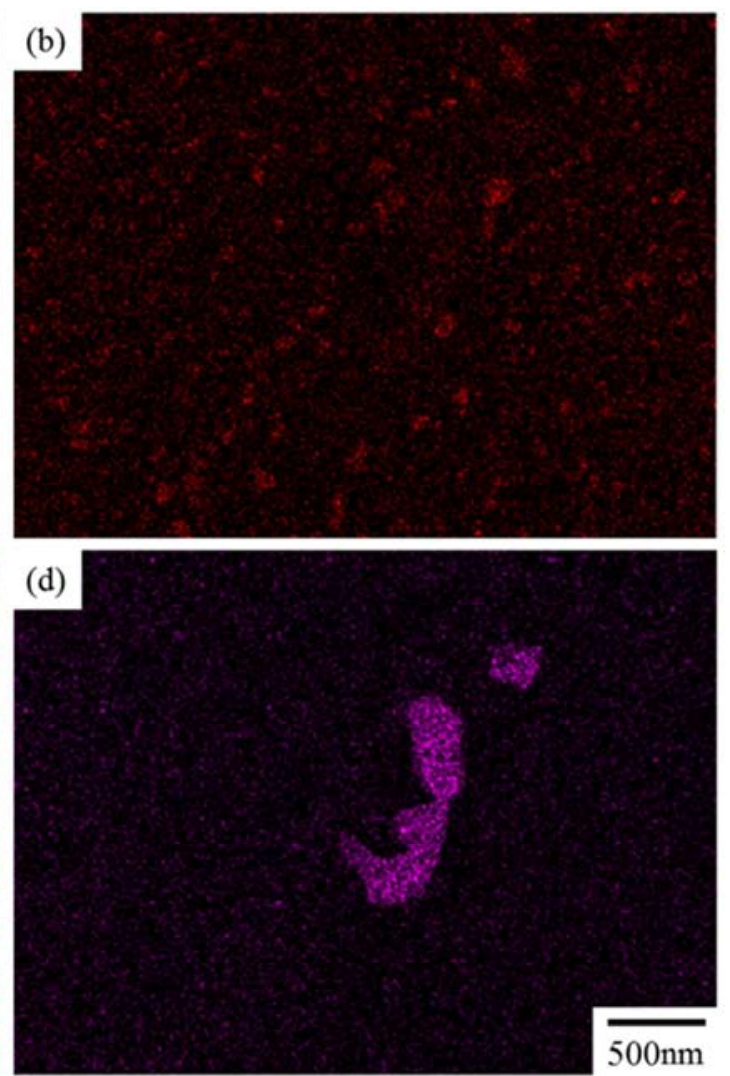

Figure 10. Scanning transmission electron images of virgin Alloy617 interrupted at $750^{\circ} \mathrm{C}, 170 \mathrm{MPa}(\mathrm{t}=997 \mathrm{~h},(\mathrm{a}) \mathrm{BF}$, (b) $\mathrm{Al}$, (c) $\mathrm{Cr}$, (d) $\mathrm{Mo})$. 
According to the previous study [9-12], precipitates rich in $\mathrm{Cr}$ near the grain boundary and in the grains were identified as $\mathrm{M}_{23} \mathrm{C}_{6}$ carbide. Precipitates rich in Mo were identified as $\mathrm{M}_{6} \mathrm{C}$ carbide and precipitates rich in $\mathrm{Al}$ were identified as the $\gamma^{\prime}$ phase as well. The BF image (a) shows the trace of the grain boundary migration. By combining this with the $\mathrm{Cr}$

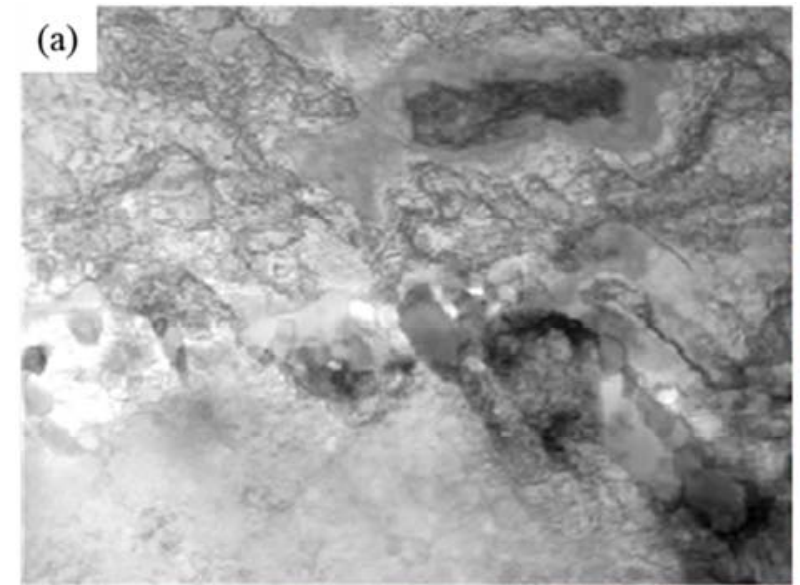

(c)

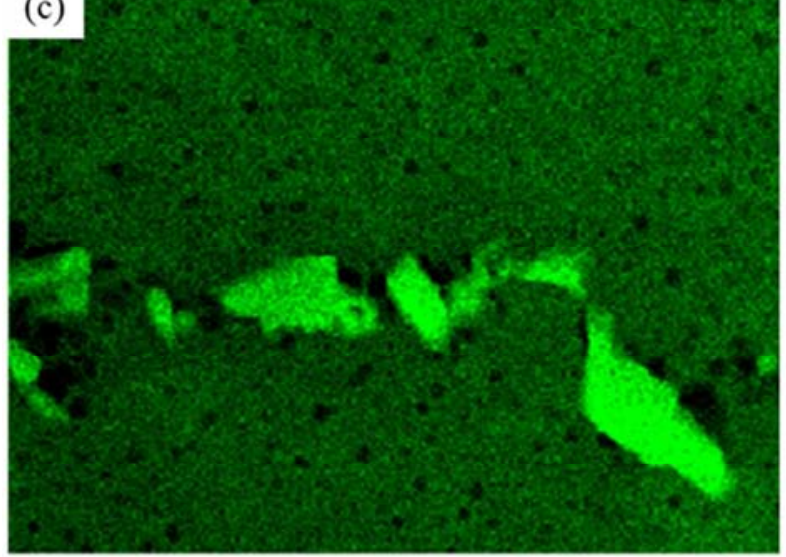

image (c), the location where $\mathrm{M}_{23} \mathrm{C}_{6}$ carbide lined up was possibly the initial grain boundary. Figure 11 shows STEM results for the pre-strained sample subjected to the creep interrupted test conducted under the same condition as that for the non-pre-strained sample shown in Figure 10.

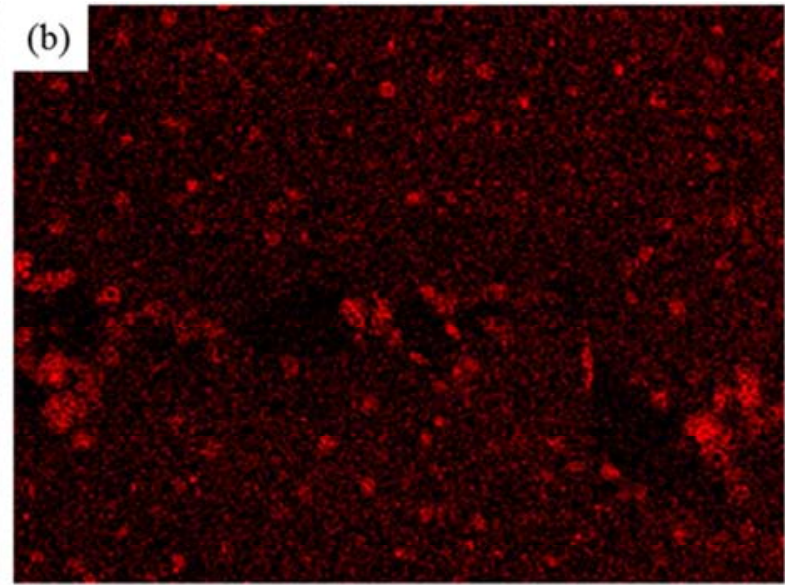

\section{(d)}

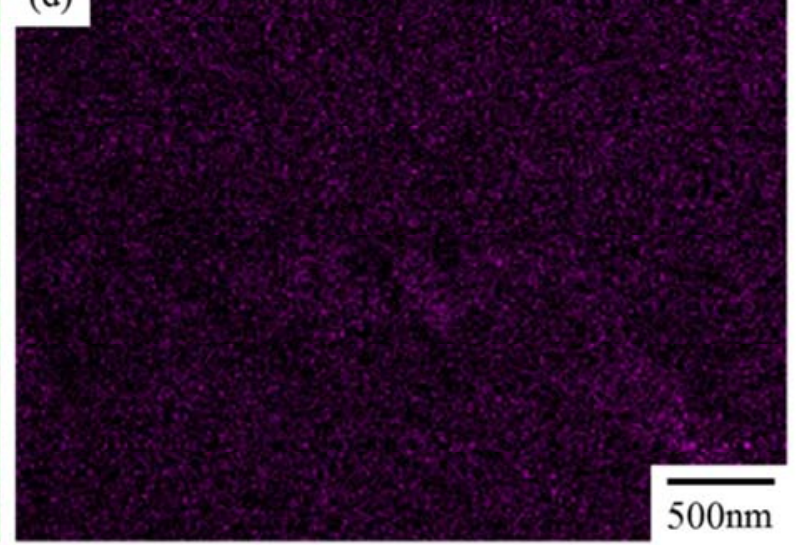

Figure 11. Scanning transmission electron images of pre-strained Alloy617 interrupted at $750^{\circ} \mathrm{C}, 170 \mathrm{MPa}(\mathrm{t}=997 \mathrm{~h}$, (a) $\mathrm{BF}$, (b) $\mathrm{Al}$, (c) $\mathrm{Cr}$, (d) $\mathrm{Mo}$ ).

$\mathrm{M}_{23} \mathrm{C}_{6}$ carbide, $\mathrm{M}_{6} \mathrm{C}$ carbide, and the $\gamma^{\prime}$ phase were also seen, as is the case with the non-pre-strained sample. Although $\mathrm{M}_{6} \mathrm{C}$ carbide was also observed in this sample, it did not seen in the Figure 11. Comparing Figure 10(b) with Figure 11(b), the amount of $\gamma^{\prime}$ phase near the grain boundary is larger in the pre-strained sample than in the non-pre-strained sample. As for $\mathrm{M}_{23} \mathrm{C}_{6}$ carbide, a comparison of Figure 10(c) and Figure 11(c) shows that the amount of this carbide near the grain boundary is larger in the pre-strained sample and the size is larger as well. In addition, no $\mathrm{M}_{23} \mathrm{C}_{6}$ carbide is seen in the grains, unlike the non-pre-strained sample. From SEM and STEM observations, it is found that (1) the amount of precipitates at the grain boundaries in the non-pre-strained sample is smaller than that in the pre-strained sample and (2) grain boundary migration is seen in the non-pre-strained sample. To examine the sort of precipitates and the state of the grain boundary in the non-pre-strained sample in more detail, an EBSD pattern and backscattered electron images (BEIs) were analyzed. Figure 12 shows the results taken from the non-pre-strained sample interrupted creep (test conditions: $750^{\circ} \mathrm{C}, 170 \mathrm{MPa}$, interrupted after 997 hours). 


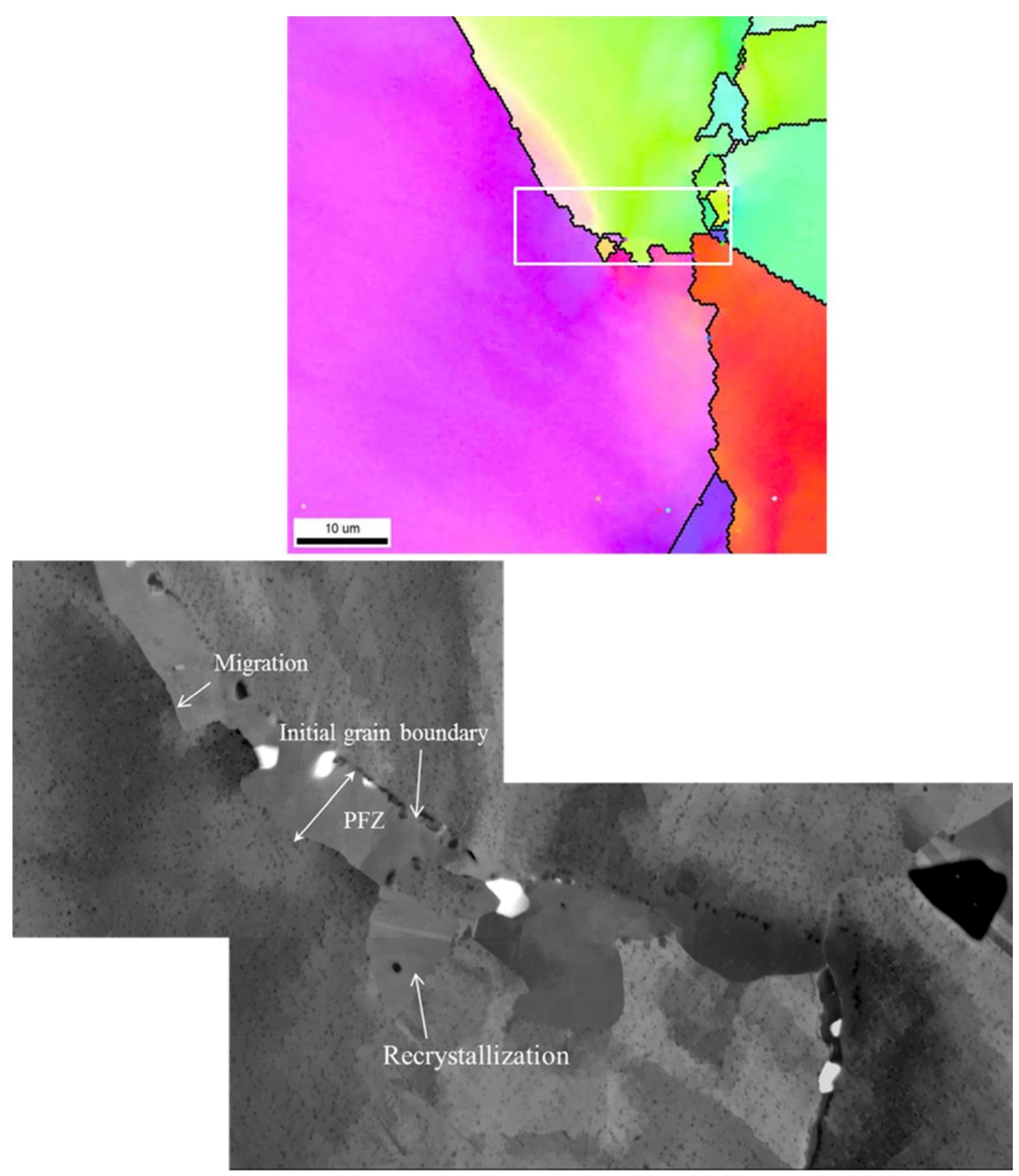

Figure 12. Results of (a) IPF image, (b) backscattered electron image of Alloy617 interrupted at $750^{\circ} \mathrm{C}, 170 \mathrm{MPa}$.

The white bordered area in the inverse pole figure (IPF) image (Figure 12(a)) almost matches the area in the BEIs (Figure 12(b)). The IPF map shows that the grain boundary is considerably curved and strain contrast is seen around it. In addition, there is a trace of grain boundary migration as is the case with the TEM observation. In that area, no $\gamma^{\prime}$ phase is seen [20-22].

\subsection{Strain Distribution in the Non-pre-strained and Pre-strained Samples}

To clarify the reason why the amount of precipitates in the pre-strained sample became large near the grain boundary, the sample before creep test was observed with EBSD measurement. Figure 13 shows the results. (a) is the KAM (Kernel Average Misorientaion) map of the non-pre-strained sample and (b) is its KAM distribution. (c) is the KAM map of the pre-strained sample and (d) is its KAM distribution. 

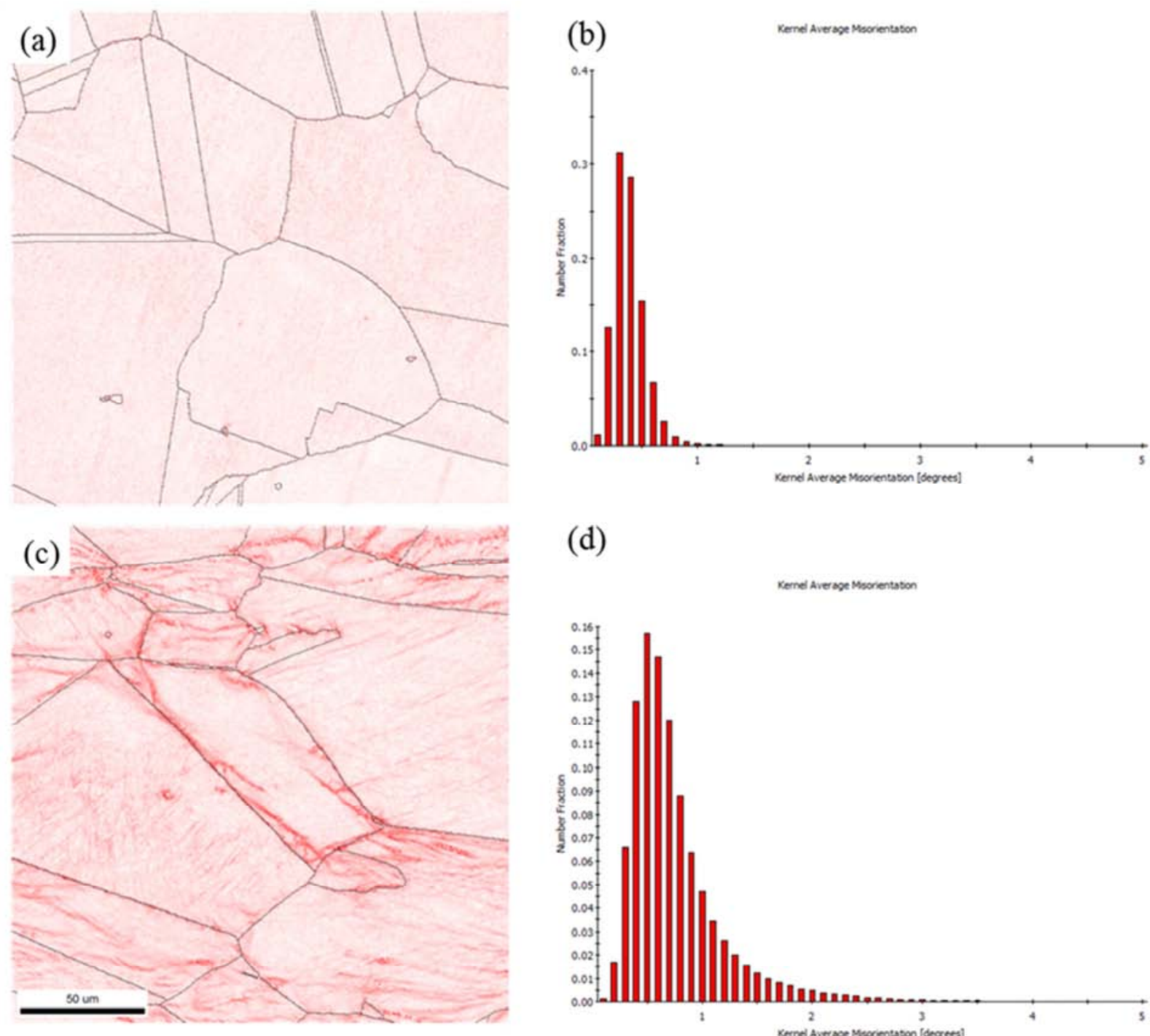

(d)

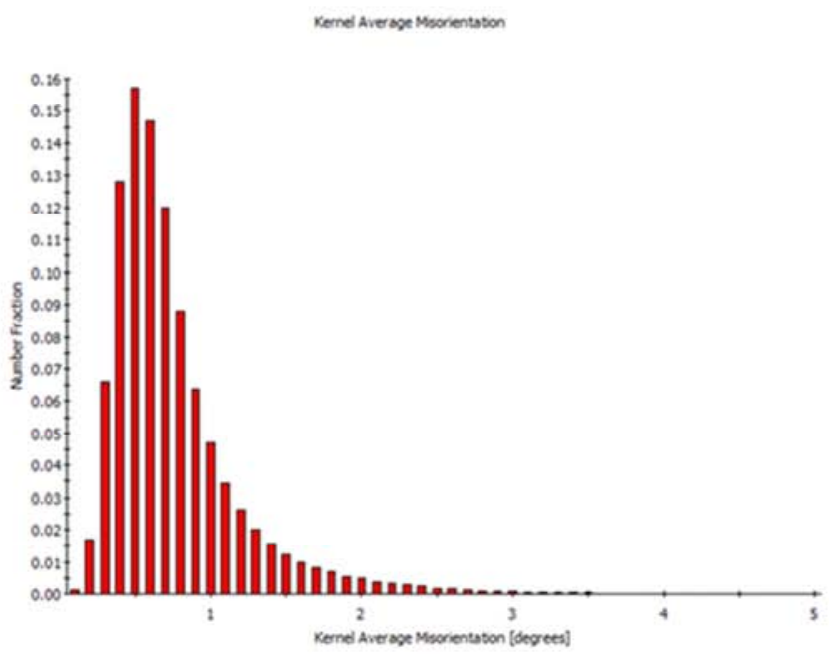

Figure 13. Comparison of KAM of virgin alloy with pre-strained alloy (a) KAM map of virgin alloy, (b) KAM distribution of virgin alloy, (c) KAM map of pre-strained alloy, (d) KAM distribution of pre-strained alloy.

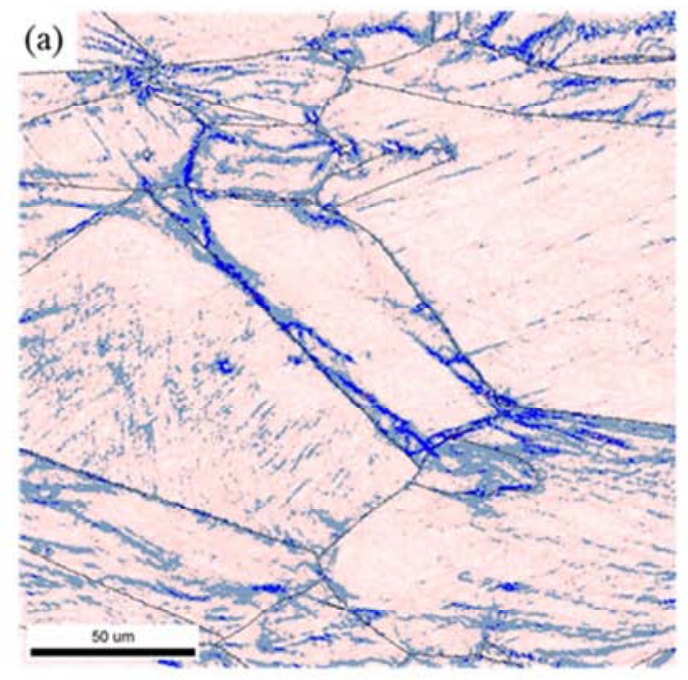

(b)

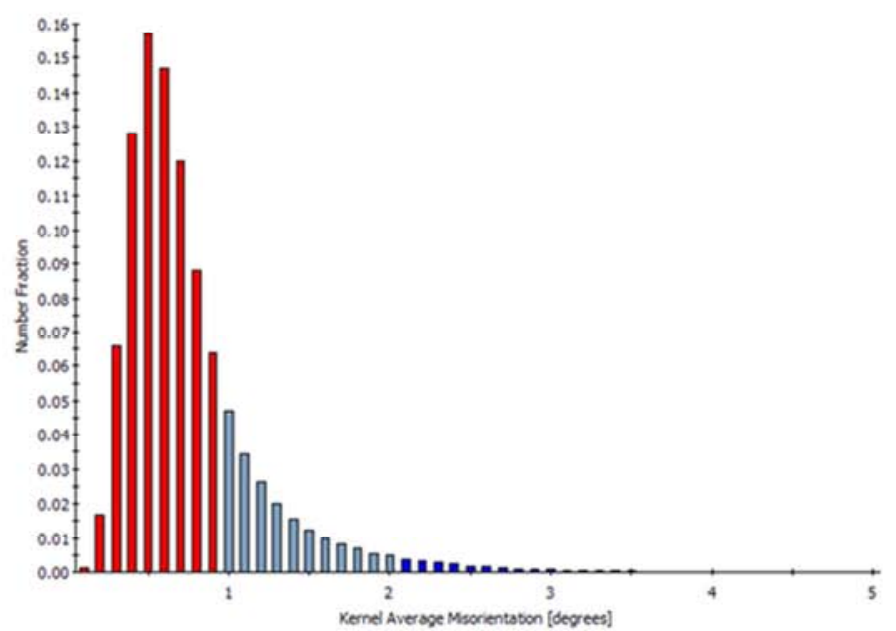

Figure 14. Results of KAM of pre-strained alloy (a) KAM map, (b) KAM distribution (the grain boundaries $1-2^{\circ}$ map and the grain boundaries $>2^{\circ}$ map are drawn with sky blue lines and blue lines). 
It means in Figure 13 that as the red color becomes darker on the KAM map, the local misorientation (i.e. dislocation density) is larger. There are no regions with large KAM values in the non-pre-strained sample. On the other hand, in the pre-strained sample, regions with large KAM values are locally seen near the grain boundaries. These are also seen in the KAM distributions in Figures 13(b) and (d). In the non-pre-strained sample, the peak is around $0.3^{\circ}$ and at the KAM values of $1^{\circ}$ or more, whereas in the pre-strained sample, the ratio of the KAM values of $1^{\circ}$ or more is larger and the ratio of 2 to $3^{\circ}$ or more is also larger than in the non-pre-strained sample. In order to make clear the regions where the KAM values are $1^{\circ}$ or more (i.e. sections with large dislocation density) in the pre-strained sample, the sections with KAM values of 1 to $2^{\circ}$ are shown in sky blue color and the regions with $3^{\circ}$ or more are shown in blue color in Figure 14.

It is found in Figure 14 that most of the regions with KAM values of $3^{\circ}$ or more exist near the grain boundaries. It is considered that many dislocations introduced by the
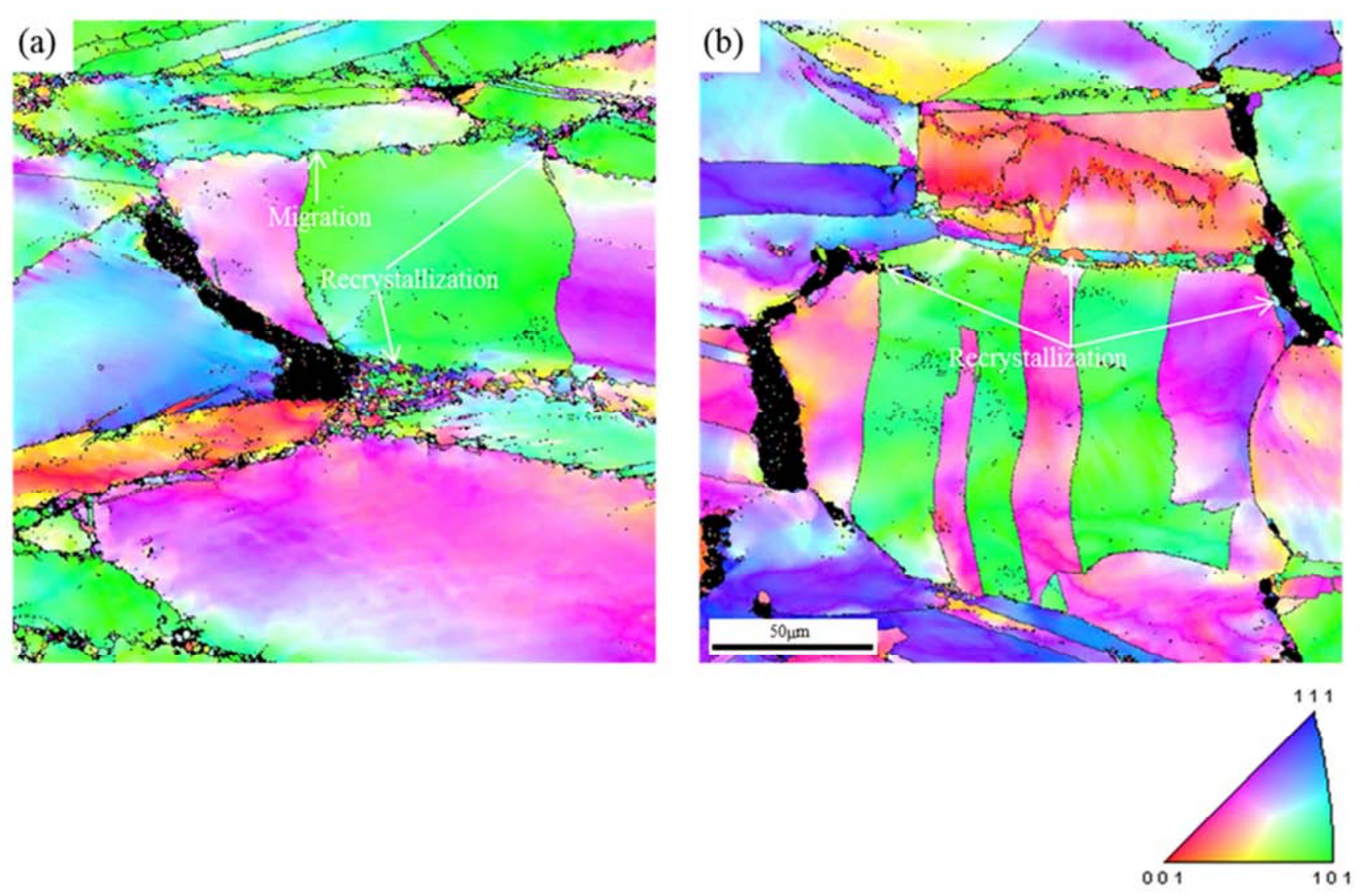

pre-strain have accumulated near grain boundaries. These facts indicate that a large amount of precipitates near grain boundaries observed in the pre-strained sample is due to the precipitation on the dislocation accumulated near the grain boundaries. It has been reported that dislocations introduced by cold working in Ni base alloys and austenitic steel become precipitation sites and they accelerate precipitation $[22,23]$. In addition, it has been reported that an increase in precipitates near grain boundaries improves the creep rupture strength $[24,25]$. It is considered that the precipitates near grain boundaries in the pre-strained sample play an important role to reduce grain boundary migration and thereby prevent the formation of zigzag grain boundaries and reduce the formation of weak conditions such as PFZ and recrystallization, which results in an improved creep strength.

Figure 15 shows the IPF maps of the samples ruptured at $750^{\circ} \mathrm{C}$ under $170 \mathrm{MPa}$. (a) (non-pre-strained sample) and (b) (pre-strained sample) show that recrystallization have developed at the grain boundaries and at crack initiation sites for both samples.

Figure 15. IPF images with EBSD of Alloy 617 ruptured at $750^{\circ} \mathrm{C}, 170 \mathrm{MPa}$ (a) Virgin, (b) pre-strain at $30 \%$.

As mentioned in the section in 3.1, the rupture time of the non-pre-strained sample is shorter than that of the pre-strained sample. This fact is probably because many recrystallization grains were formed at the grain boundaries, as is seen Figure 15(a). In other words, weak conditions are quickly formed in the non-pre-strained sample comparing to the pre-strained sample.

\subsection{Differences in Creep Deformation Behaviors Depending on Stress}

In the previous section, the reason why the creep rupture strength of the pre-strained sample at low stress conditions is higher than that of the non-pre-strained sample was explained. 
In this section, the threshold stress between the high stress condition and the low stress condition is mentioned. It has been reported that the threshold is consistent with the stress at which instantaneous plastic strain occurs in creep test when stress is applied (athermal yield stress) [26-28]. When the test stress is equal to or higher than the threshold stress, large plastic deformation occurs and many dislocations are introduced, which work-hardens the test samples. It is considered that these introduced dislocations affect creep deformation behaviors and that the amount of the dislocations varies whether the applied stress is higher or lower than the threshold stress. In this study, the stress at which instantaneous plastic strain occurred after application of stress was determined from Figure 4 . The threshold stress for the non-pre-strained sample was approximately $300 \mathrm{MPa}$ at $700^{\circ} \mathrm{C}$ and $170 \mathrm{MPa}$ or more at $750^{\circ} \mathrm{C}$. In this research, all creep tests at $700^{\circ} \mathrm{C}$ correspond to conditions greater than the athermal yield stress. Therefore, the non-pre-strained sample is possibly work-hardened when stress is applied, and hence the creep strength becomes the same as that of the pre-strained sample. Meanwhile, all the test stresses at $750^{\circ} \mathrm{C}$ creep are equal to or lower than the threshold stress. Therefore, the non-pre-strained samples are not work-hardened when stress is applied and thereby the microstructural difference is observed, as mentioned in 3.4. As a result, the creep rupture time of the non-pre-strained sample becomes shorter than that of the pre-strained sample.

From the above, it is considered that the dislocations introduced before the creep deformation promotes precipitation of $\gamma^{\prime}$ phase and $\mathrm{M}_{23} \mathrm{C}_{6}$ carbide near the grain boundary and they delay formation of PFZ. Therefore, the creep rupture strength of Alloy 617 increases due to introduction of dislocations.

\section{Conclusion}

The effect of cold working on the creep rupture strength of Alloy617 was investigated. The obtained results are as follows.

(1) At high stress conditions, the creep rupture time of the non-pre-strained samples are similar to those of the pre-strained samples. Meanwhile, at low stress conditions, the creep rupture time of the pre-strained samples are longer than those of the non-pre-strained samples. The threshold stress is almost consistent with the stress at which instantaneous strain in the non-pre-strained sample occurs.

(2) Both the transient creep rate and the minimum creep rate of the pre-strained samples are smaller than those of the non-pre-strained samples. The value of minimum creep rate is smaller by approximately one order of magnitude. In addition, it is found that applying pre-strain delays both the time to reach the minimum creep rate and time at which acceleration begins.

(3) Weak conditions such as PFZ and recrystallization grains in the non-pre-strained sample are formed at an earlier stage of creep compared to the pre-strained sample.

(4) The density of precipitates near the grain boundaries is larger in the pre-strained sample than that in the non-pre-strained sample. It is considered from this result that at low stress conditions, the precipitates near the grain boundaries in the pre-strained sample play an important role to pin the grain boundaries and that they delay the formation of weak conditions resulting in extension of the creep rupture time. However, at high stress conditions, the non-pre-strained sample is possibly work-hardened when stress is applied and this creep strength becomes same as that of the pre-strained sample.

\section{References}

[1] H. Umaki, I. Kajigaya, T. Kunihiro, T. Totsuka, M. Nakashiro and T. Kume, Application of Large Diameter Seam Welded Pipes and Header of Super 9Cr Steel for 700MW Coal-Fired Boiler with $593^{\circ} \mathrm{C}$ Reheat Steam Temperature, Ishikawajima-Harima Engineering Review. 31 (1991) 339-345 (in Japanese).

[2] S. J. Patel, J. J. DeBarbadillo, B. A. Baker, R. D. Gollihue, Nickel Base Superalloys for Next Generation Coal Fired AUSC Power Plants, Procedia Engineering. 55 (2013) 246-252.

[3] R. Viswanathan, J. F. Henry, J. Tanzosh, G. Stanko, J. Shingledecker, B. Vitalis and R. Purgert, U.S. Program on Materials Technology for Ultra-Supercritical Coal Power Plants, Journal of Materials Engineering and Performance. 14, (2005) 281-292.

[4] J. P. Shingledecker, Testing and Analysis of Full-Scale Creep-Rupture Experiments on Inconel Alloy 740 Cold-Formed Tubing, Journal of Materials Engineering and Performance. 22 (2013) 454-462.

[5] M. Fukuda, Advanced USC, Journal of the Thermal and Nuclear Power. 62 (2011) 731-740 (in Japanese).

[6] F. Abe, Research and Development of Heat-Resistant Materials for Advanced USC Power Plants with Steam Temperatures of $700^{\circ} \mathrm{C}$ and Above, Engineering. 1 (2015) 211-224.

[7] J. Klower, R. U. Husemann, M. Bader, Development of Nickel Alloys Based on Alloy617 for Components in $700^{\circ} \mathrm{C}$ Power Plants, Procedia Engineering. 55 (2013) 226-231.

[8] K. Kubusiro, K. Nomura, H. Nakagawa, Y. Ohkuma and K. Muroki, Development of fabrication technology for the A-USC boiler, Proceedings of the International Conference on Power Engineering-15 (2015).

[9] W. Ren and R. Swimdeman, A Review Paper on Aging Effects in Alloy 617 for Gen IV Nuclear Reactor Applications, Transactions of the ASME. 131 (2009).

[10] H. Nickel, Characterization of metallic and ceramic high temperature materials for energy systems by means of atomic spectroscopy, Pure \& Appl. Chem. 65 (1993) 2481-2500.

[11] Q. Wu, H. Song, R. W. Swindeman, J. P. Shingledecker, and V. K. Vasudevan, Microstructure of Long-Term Aged IN617 Ni-Base Superalloy, Metallurgical and Materials Transactions A. 39A (2008) 2569-2585.

[12] E. Gariboldi, M. Cabibbob, S. Spigarellib and D. Ripamonti, Investigation on precipitation phenomena of $\mathrm{Ni}-22 \mathrm{Cr}-12 \mathrm{Co}-9 \mathrm{Mo}$ alloy aged and crept at high temperature, International Journal of Pressure Vessels and Piping. 85 (2008) 63-71. 
[13] K. Okada, Y. Semba, S. Ishikawa and M. Yoshizawa, Effect of cold working on creep properties of a $23 \mathrm{Cr}-45 \mathrm{Ni}-7 \mathrm{~W}$ alloy, Proceedings of the $163^{\text {rd }}$ ISIJ Meeting. 25 (2012) 405 (in Japanese).

[14] K. Kubushiro, Y. Shioda and K. Nomura, Effect of Pre-strain on the Creep Strength of Ni-Based Alloys for A-USC Boilers, Trans Indian Inst Met. DOI 10.1007/s12666-016-0919-3.

[15] A. Iseda, M. Kubota, Y. Hayase, S. Yamamoto and K. Yoshikawa, Application and Properties of Modified 9Cr-1Mo Steel Tubes and Pipe for Fossil-fired Power Plants, The Sumitomo Search. 36 (1988) (in Japanese).

[16] S. Caminada, G. Cumino, L. Cipolla and A. Di Gianfrancesco, Cold bending of advanced ferritic steels: ASTM grades T23, T91, T92, International Journal of Pressure Vessels and Piping. 86 (2009) 853-861.

[17] Y. Kurata and H. Nakajima, Creep properties of $20 \%$ cold-worked Hastelloy XR, Journal of Nuclear Materials. 228 (1996) 176-183.

[18] K. Mino, A. Ohtomo and Y. Saiga, Effect of Grain Boundary Migration and Recrystallization on the Creep Strength of Inconel 617, Tetsu-to-Hagane. 63 (1977) 106-114 (in Japanese).

[19] S. Chomette, J. M. Gentzbittel and B. Viguier, Creep behaviour of as received, aged and cold worked INCONEL 617 at $850^{\circ} \mathrm{C}$ and $950^{\circ} \mathrm{C}$, Journal of Nuclear Materials 399 (2010) 266-274.

[20] M. Yonemura, H. Semba and M. Igarashi, Development of Microstructural Damage in Ni-Based Alloys During Creep, Metallurgical and Materials Transactions A. 47A (2016) 1898-1905.
[21] Y. Wu, M. Zhang, X. Xie, F. Lin and S. Zhao, Dynamic recrystallization of a new nickel-based alloy for $700^{\circ} \mathrm{C}$ A-USC power plant applications with different initial states: as-homogenized and as-forged, Materials Science \& Engineering A. 662 (2016) 283-295.

[22] A. Porter and B. Ralph, The recrystallization of nickel-base superalloys, Journal of material science. 16 (1981) 707-713.

[23] T. Nakazawa and H. Abo, The Effects of Some Factors on the Creep Behavior of Type 304 Stainless Steel, Tetsu-to-Hagane. 63 (1977) 82-91 (in Japanese).

[24] A. M. Elbatahgy, T. Matsuo and M. Kikuchi, Grain Boundary Precipitation Strengthening due to $\gamma^{\prime}$ Phase in High Temperature Creep of a Ni-base Superalloy, Tetsu-to-Hagane. 76 (1990) 125-132 (in Japanese).

[25] Y. Kondo, A. Ishizaki and J. Namekata, Effect of Carbide Precipitation Formed on Dislocations along Grain Boundaries on High Temperature Creep Resistance of a Ni-30Cr Alloy, Tetsu-to-Hagane. 76 (1990) 147-154 (in Japanese).

[26] K. Kimura, K. Sawada and H. Kushima, Long-Term Creep Strength Property of Advanced Ferritic Creep Resistant Steels, Proceedings of 6th Int Conf on Advanced in Materials Technology for Fossil Power Plants. (2010) 732-751.

[27] K. Sawada, K. Kubo and K. Kimura, Evaluation of Microstructural Factors of High Chromium Ferritic Steel Based on Analysis of Anelasticity Behavior at High Temperature, Tetsu-to-Hagane. 90 (2004) 835-840 (in Japanese).

[28] K. Maruyama, K. Sawada, J. Koike, H. Sato and K. Yagi, Examination of deformation mechanism maps in $2.25 \mathrm{Cr}-1 \mathrm{Mo}$ steel by creep tests at strain rates of $10^{-11}$ to $10^{-6} \mathrm{~S}^{-1}$, Materials Science and Engineering A. 224 (1997) 166-172. 